\title{
12
}

\section{Implementation Strategies for SME 4.0: Insights on Thailand}

\author{
Apichat Sopadang, Sakgasem Ramingwong, \\ Tanyanuparb Anantana, and Krisana Tamvimol
}

\subsection{Introduction}

Industry 4.0 or the 4th Industrial Revolution is referred as the advanced manufacturing environment toward the smart technology such as CyberPhysical Systems (CPS), Internet of Things (IoT), Information and Communications Technology (ICT), Enterprise Architecture (EA), and

\footnotetext{
A. Sopadang $\cdot$ S. Ramingwong $(\bowtie)$

Center of Excellence in Logistics and Supply Chain Management, Chiang Mai University, 239 Huay Kaew Road Rd., Muang District, Chiang Mai 50200, Thailand e-mail: sakgasem.ramingwong@cmu.ac.th
}
A. Sopadang e-mail: apichat.s@cmu.ac.th

A. Sopadang $\cdot$ S. Ramingwong $\cdot$ T. Anantana

Department of Industrial Engineering, Faculty of Engineering, Chiang Mai University, 239 Huay Kaew Road Rd., Muang District, Chiang Mai 50200, Thailand e-mail: tanyanuparb@step.cmu.ac.th 
Enterprise Integration (EI) (Lu 2017; Rüßmann et al. 2015). Industry 4.0 employs modern "push" technologies in "pull" applications, i.e., Internet-based and Internet of Services, which is mostly influenced by the computational power, cloud computing, and services. Industry 4.0 allows the company to foresee future products and to appropriately respond to the variety and complexity at low cost and low impact (Ganzarain and Errasti 2016). Production and logistics systems can be decentralized and integrated horizontally and vertically with the use of interconnected sensors, actors, and autonomous systems (Gilchrist 2016; Jazdi 2014). However, the integration of physical and software systems and modeling the intelligence system can be highly expensive and complicated due to the complex, dynamic, and integrated information systems (Lasi et al. 2014; Rauch et al. 2020).

The extension of Industry 4.0 goes from Smart Manufacturing to Smart Logistics, including organization and management (SME4.0 2020). The constraints comprise of SME focus, mass customization, and X-to-order environment (Mihiotis 2014), economic, ecological, and social sustainability (Brozzi et al. 2020; Gabriel and Pessl 2016; Prause 2015), lean philosophy, changeability, and flexibility. The enablers include IoT, Big Data, CPS (Lee et al. 2015), smart sensors, digitalization, and automation.

Industry 4.0 has become the new normal for large enterprises where organization and business models can be redesigned and investment can be made viably (Safar et al. 2018). However, implementing Industry 4.0 to SMEs is yet challenging due to their limited resources, knowledge, and investment (Bär et al. 2018; Ganzarain and Errasti 2016; Ramingwong et al. 2019; Ramingwong and Manopiniwes 2019). In such a quest, SME

\section{T. Anantana}

Science and Technology Park, Chiang Mai University, 155 Moo 2 Mae Hia, Muang District, Chiang Mai 50100, Thailand

K. Tamvimol

Wangree Agriculture Technology Institute, Wangree Health Factory Co., Ltd, 143 Moo 12 Khaopra, Muang District, Nakornnayok 26000, Thailand e-mail: krisana@wangreefresh.com 
4.0 has been simply defined as the implementation of Industry 4.0 to SME (Matt and Rauch 2020; Sopadang et al. 2020).

Therefore, it is the aim of this study to investigate how SMEs can become SME 4.0. The development and implementation strategies for SME 4.0 are of interest. The study explores and discusses the success of a Thai start-up SME as case study by aligning with the developed meta-model of implementation strategies for SME 4.0.

\subsection{Implementation Strategies for SMEs}

It is important that SMEs must develop and implement Industry 4.0 strategies to become SME 4.0 according to their strength, resources, and investment. To date, there are extensive works regarding the SME 4.0 implementation including Industry 4.0 maturity models for SMEs (Chonsawat and Sopadang 2019; Ganzarain and Errasti 2016; Rauch 2020), the procedure of manufacturing resources migration toward Industry 4.0 (Pérez et al. 2018), smart SME 4.0 implementation toolkits (Sopadang et al. 2020) as well as requirement mapping and roadmaps for SME 4.0 (Modrak et al. 2019). With different views of the cause, the proposed model or methodology in this literature is diversified. However, most of the focus is on the organization itself. This chapter further investigates the external bodies, by which in this case the collaboration of universities and tech-development agencies are enveloped. The collaboration is assumed as the triple-helix model of innovation (Galvao et al. 2019; Leydesdorff 2010; Nakwa and Zawdie 2016).

Figure 12.1 illustrates the meta-model of implementation strategies for SME 4.0 developed and used in this case study. The model is triple helix where the organization works with universities and tech-development agencies on the inside-out and outside-in approaches.

To develop suitable strategies for SME implementation, the development plan and analysis phases are required. The development plan is to develop technology blueprint, which is the result of industrial research and capacity development. Whereas the analysis phase refers to gap analysis from business trend analysis and business foresight. The 
following sections discuss the three phases of the model, i.e., Analysis, Development Plan, and Implementation Strategies.

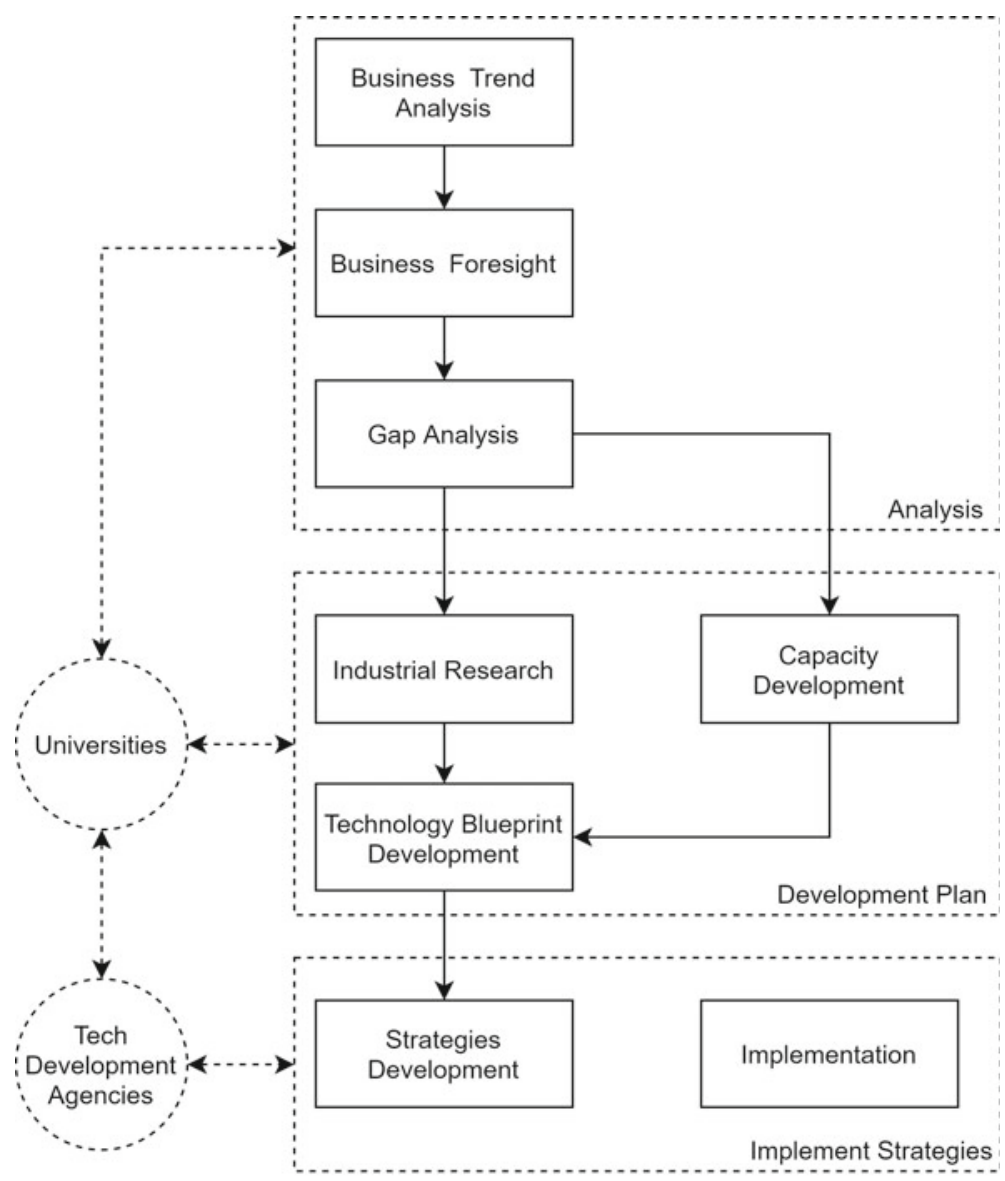

Organization

Fig. 12.1 Implementation strategies for SME 4.0 meta-model 


\subsubsection{Phase 1-Analysis}

The first analysis phase comprises three steps, i.e., (1) Business Trend Analysis, (2) Business Foresight, and (3) Gap Analysis.

"Business Trend Analysis" is the first step of the meta-model. It is the process of comparing business over time to identify any consistent trends. The developed strategies must correspond with these trends and the business goals. The trend analysis comprises of three sub-steps, i.e., review of KPIs, trend analysis, and business benchmarking (see Fig. 12.2). Firstly, the review of KPIs must include financial and non-financial KPIs (Tippayawong et al. 2019) both in the well-known Balance Scorecard (BSC) approach (Kaplan and Norton 1998) and sustainable concepts (Gabriel and Pessl 2016; Prause 2015; Stubbs and Cocklin 2008). Then, the trend analysis can be Time Series Analysis or Multivariate Analysis. This is to assist Business Decision Making. Multiple Criteria Decision Making (MCDM) is often used for such applications. Finally, it is necessary to do business benchmarking.

Once the business trend is analyzed, it is necessary to conduct "Business Foresight" to conceptualize practices, capabilities, and ability of firms. The foresight enables firms to detect changes, understand the

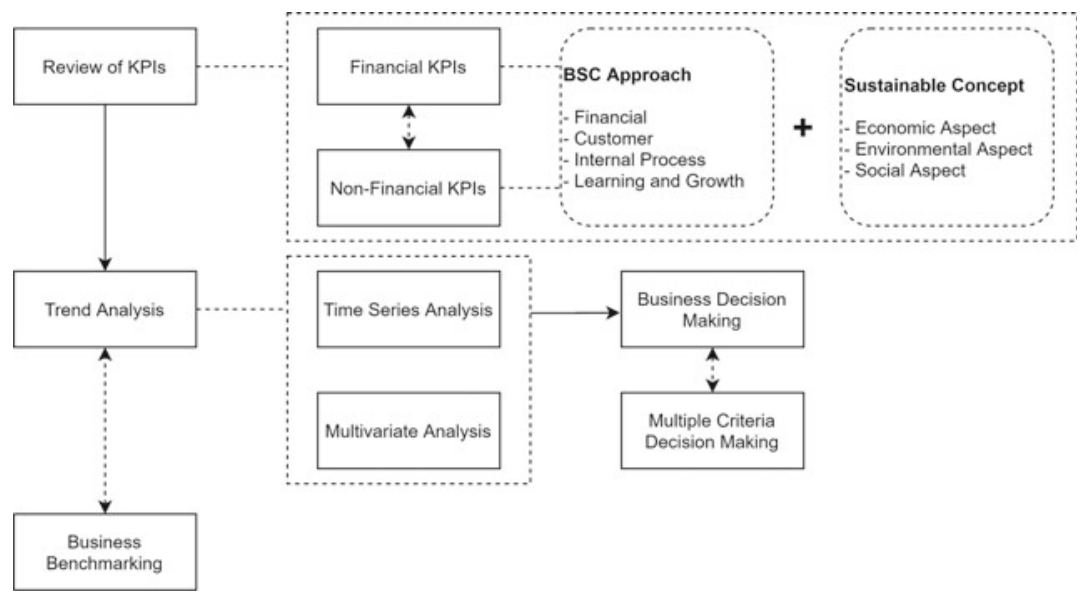

Fig. 12.2 Business trend analysis concept 
consequences, and address appropriate responding actions (Rohrbeck 2010; Rohrbeck et al. 2015). The business foresight comprises six sub-steps, i.e., framework development, environment analysis, scanning signal analysis, scenario building, scenario analysis, and strategic development and planning (see Fig. 12.3).

The final step of Phase 1 is the "Gap Analysis." The gap analysis involves the comparison of the actual performance with the desired performance or the foresighted goals. Three gaps must be identified before setting up the development plan in Phase 2. The gaps are from product/service delivery, perceived service, expected product/service, and

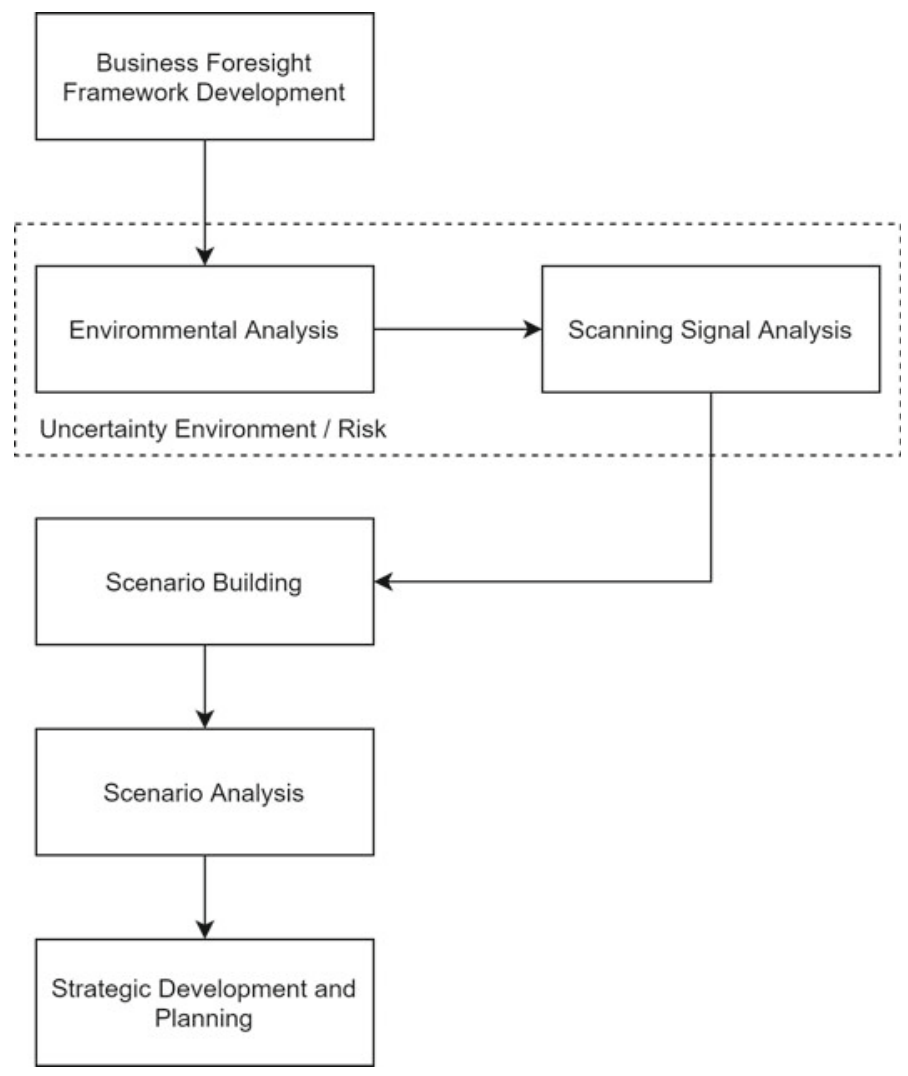

Fig. 12.3 Business foresight concept 


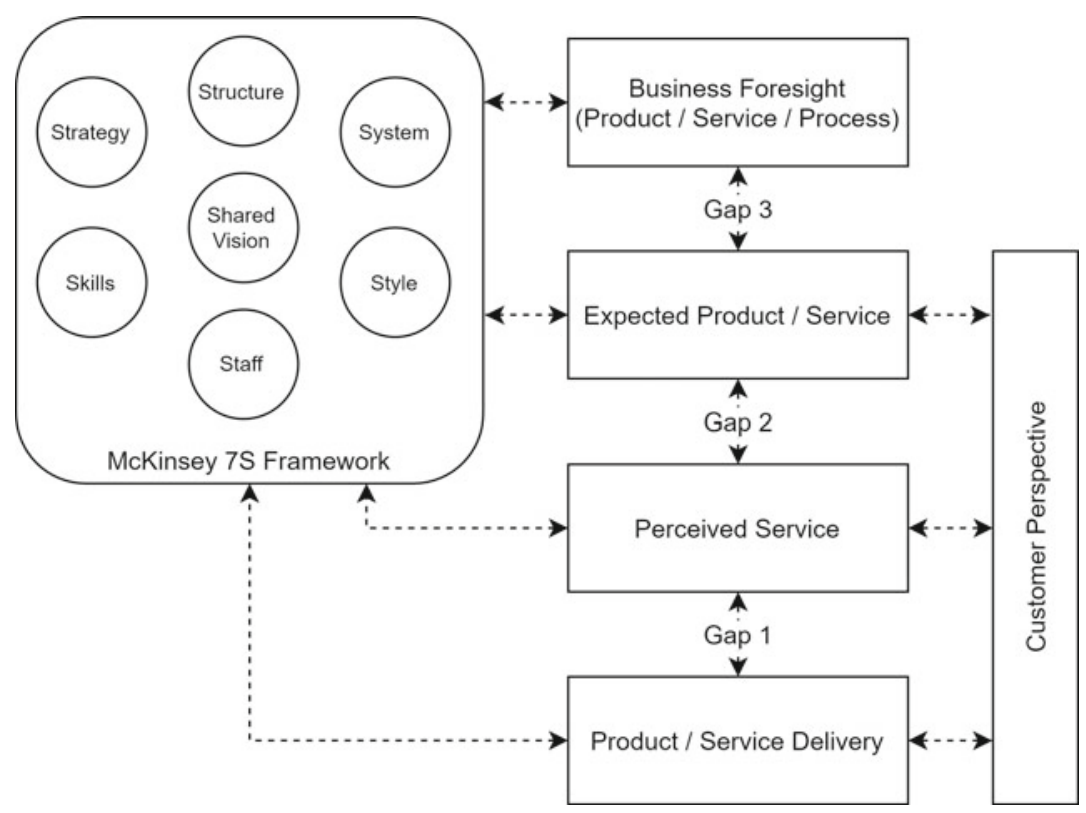

Fig. 12.4 Gap analysis concept

business foresight (see Fig. 12.4). Here, they shall be addressed in corresponding to the McKinsey 7S Framework (Hanafizadeh and Ravasan 2011; Singh 2013) and the customer perspective.

\subsubsection{Phase 2-Development Plan}

Phase 2 (Development Plan) comprises of three steps, i.e., Industrial Research, Capacity Development, and Technology Blueprint Development. They are as follows.

According to Commission Regulation (EU) No 651/2014 of 17 June 2014, Industrial Research is defined as "the planned research or critical investigation aimed at the acquisition of new knowledge and skills for developing new products, processes or services or for bringing about a significant improvement in existing products, processes or services. It comprises the creation of components parts of complex systems, and may 


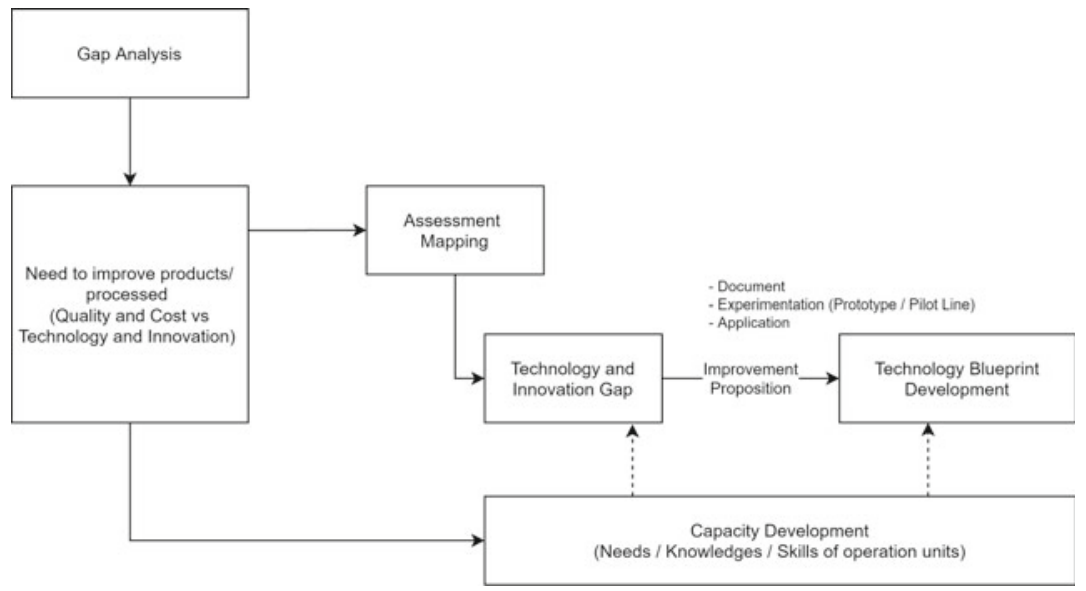

Fig. 12.5 Development plan concept

include the construction of prototypes in a laboratory environment or in an environment with simulated interfaces to existing systems as well as of pilot lines, when necessary for the industrial research and notably for generic technology validation" (add reference).

Therefore, the development plan phase requires input from the gap analysis in the previous step to identify the need to improve products/processed in terms of quality and cost with technology and innovation. Then, the assessment mapping is to yield technology and innovation gap. This must be aligned with the capacity development, i.e., needs, knowledge, and skills of operation units. This is to address the improvement proposition and thus to develop a technology blueprint (see Fig. 12.5).

While the first two phases involve universities and think tank, Phase 3 is mostly supported by tech-development agencies.

\subsubsection{Phase 3-Implementation Strategies}

This phase involves the development of strategies and implementation. Where the strategic development and planning concerns business strategy, business process, and business organization/function, these yield 


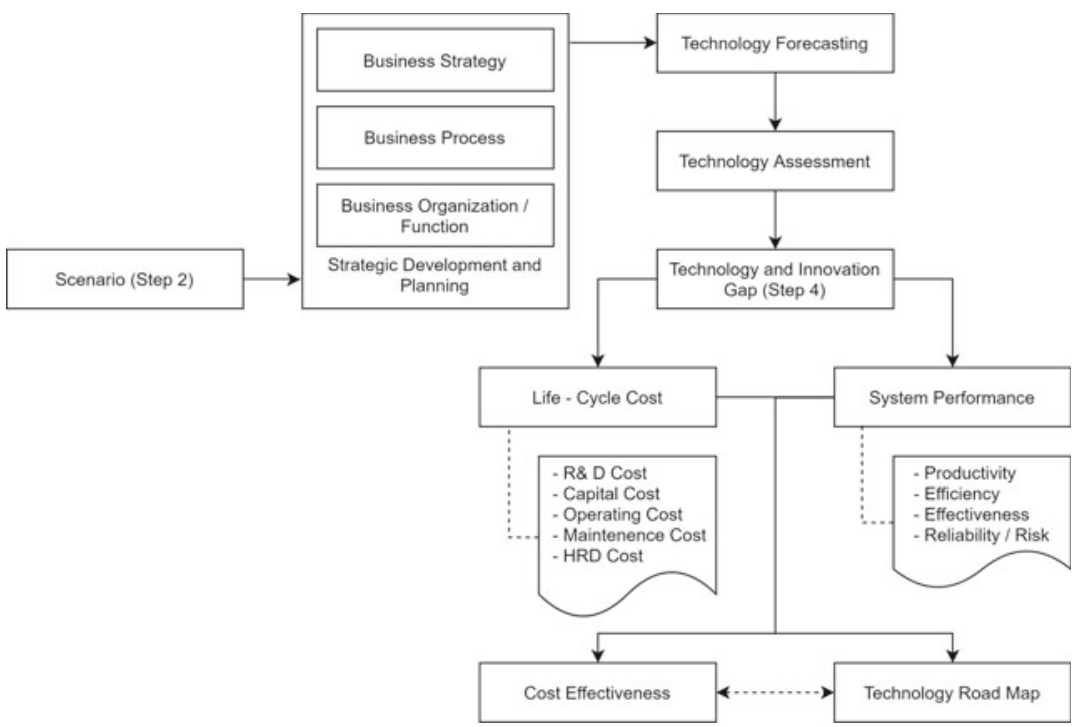

Fig. 12.6 Implementation strategies concept

the technology forecasting, assessment, and hence technology and innovation gap. The consideration is then on life-cycle cost and system performance. Here, the life-cycle cost can be research and development (R\&D) cost, capital cost, operation cost, maintenance cost, or human resource development cost. The system performance can be productivity, efficiency, effectiveness, and reliability/ risk. Finally, the technology roadmap can be reached with cost-effectiveness (see Fig. 12.6).

\subsection{Industry 4.0 Implementation in Thailand}

Thai industry has started to incorporate Industry 4.0 to its production system (Hotrawaisaya et al. 2019). Thailand enjoyed of several Industry 4.0 supporting policies from the Thai government, especially industrial transformation, ICT adoption, re-skilling, and e-government (Kohpaiboon 2020; Chinachoti 2018). However, most technological investment, expected at 1 billion USD in 2020, is on 10 targeted industries according 
to Thailand 4.0 development scheme, i.e., next-generation automotive, intelligent electronics, advanced agriculture and biotechnology, food processing and tourism, digital, robotics and automation, aviation and logistics, biofuels and biochemicals and medical hub (Kumpirarusk and Rohitratana 2018).

To date, Industry 4.0 implementation has become evident in several advanced large enterprises in the automotive industry, electronic industry, pharmaceutical industry, smart farming (Chetthamrongchai and Jermsittiparsert 2020; Jones and Pimdee 2017; Phungphol 2018; Tippayawong et al. 2016). Yet, the campaign is highly challenging (Korkueasuebsai and Pornsing 2018; Laosiritaworn and Chattinnawat 2019).

Thailand defines SMEs as companies with no more than 200 employees and 2 million THB in assets. According to the Office of Small and Medium Enterprises Promotion (OSMEP) of Thailand, there are 3 million SMEs. This SME sector contributes up to $43 \%$ of Thailand's GDP in 2019. SMEs make up $99.6 \%$ of total enterprises in the country, creating more than 10.5 million jobs.

However, according to Cisco APAC SMB digital maturity index, Thai SMEs digital readiness is low, ranked 11th out of 14 countries in AsiaPacific. Thai SMEs are identified at the stage of digitally indifferent, i.e., reactive to market changes, digital efforts do not exist, no automation (the majority of processes are manual), digital technologies are not used, and not using cloud resources. Besides, Thai SMEs are lack of customer data, lack of digital skills and talent, and lack of a digital mindset.

Investment in information technology or even automation systems alone can be difficult. Financial risk along with managerial risk can be absolute. Therefore, the implementation of SME 4.0 for Thai SMEs has been scarce (Dallasega et al. 2019; Munkongsujarit 2016).

The Thai government has foreseen the opportunity and therefore assigned OSMEP to support SMEs by providing an online platform for $\mathrm{B} 2 \mathrm{~B}$ sales, training updates, and activities that will boost up the combined revenue of Thai SMEs to 2.3 trillion THB within the next five years. Moreover, there are financial supports and promotion from the board of Investment of Thailand (BOI), National Board of SMEs Promotion, and also financial providers, especially, Small and Medium 
Enterprise Development Bank of Thailand (SME Bank). This expects to stimulate SMEs to become "smarter" and supportive to the SME 4.0 journey.

\subsection{Case Study-Thai Agritech SME}

The case study SME is a plant factory start-up in Thailand. The company is named "Wangree Health Factory Co., Ltd.". The company is inspired and initiated under an innovation ecosystem of Thailand, by which the private sector has been groomed by the university and government agencies. The project was called "STI Policy Management Program (PMP)," which is a series of training, networking, and industrial visit, hosted by the Ministry of Science and Technology in 2015. The case study company was established as a result of the project, leading to the business model of Thailand's first Agritech SME.

The company firstly aims at advancing the agriculture industry, being a Tech start-up. The idea is to upgrade the traditional agriculture industry, which is low-value-added to advanced innovative industry. Today, the agriculture industry contributes only $10 \%$ of Thailand's GDP, despite involving with nearly half of the population of Thailand from downstream to upstream. Most players in the industry are SMEs and low-tech. Cultivation and production are mostly traditional and laborintensive. Productivity is low. It is the goal of the established company to overcome these hurdles using the Industry 4.0 concept.

The first establishment of the company is a plant factory testing facility in Chiang Mai. The pilot plant was supported by Science and Technology Park of Chiang Mai University and funded by the National Science Technology and Innovation Policy Office (STI) and National Science and Technology Development Agency (NSTDA), Ministry of Science and Technology of Thailand. 


\subsubsection{Business Idea of Agritech}

Following the business idea development, the marketing survey is conducted first to investigate the expected demand, if it is aligned with the possible planned supply. Demand-side survey suggests that there is a considerable volume of the segmented customers who need clean, fresh, high-quality vegetables at a low price and at their convenience (Sukkarat and Athinuwat 2020). Expected sales volume, profit, and Return on Investment (ROI) are feasible if mass-produced in the economy of scale. Moreover, the business idea also addresses the sustainable, non-financial key performance indicators (KPI) as the food safety and quality as well as the environmental impact of the vegetable to be produced.

Looking at today agriculture industry, organic and hydroponic farms are globally flourishing and technologically saturated. Both agricultural techniques can address the needs of the customer with further benefit to the environmental and social perspectives. The cost of organic and hydroponic are comparable. However, organic is seasonal and the productivity is relatively low. It is pesticide-free but the size of the vegetable is normally smaller.

Here, the production resources are considered as the benchmarking of these two alternative technologies. To produce a vegetable of 5 tons/ month, an organic farm may require 10 rais (1.6 hectares) of land, a 3 million liter of water, and a labor of 20. Maximum production is normally 6 crops per year. On the other hand, a hydroponic farm may require 6 rais ( 0.96 hectares) of land, 1.8 million liters of water, and a labor of 20. Possible productivity can reach up to 8-12 crops per year. Therefore, the Business Trend Analysis suggests that the company shall focus on the more superlative hydroponic option (see Fig. 12.7).

According to the study by Kasikorn Research Center, the domestic organic market size has been expanded to 2700-2900 million THB in 2019 , with an annual growth of $10 \%$. Demand has been driven mostly by the millennials and aging society. These customer segments account for almost $40 \%$ of the Thai population. 


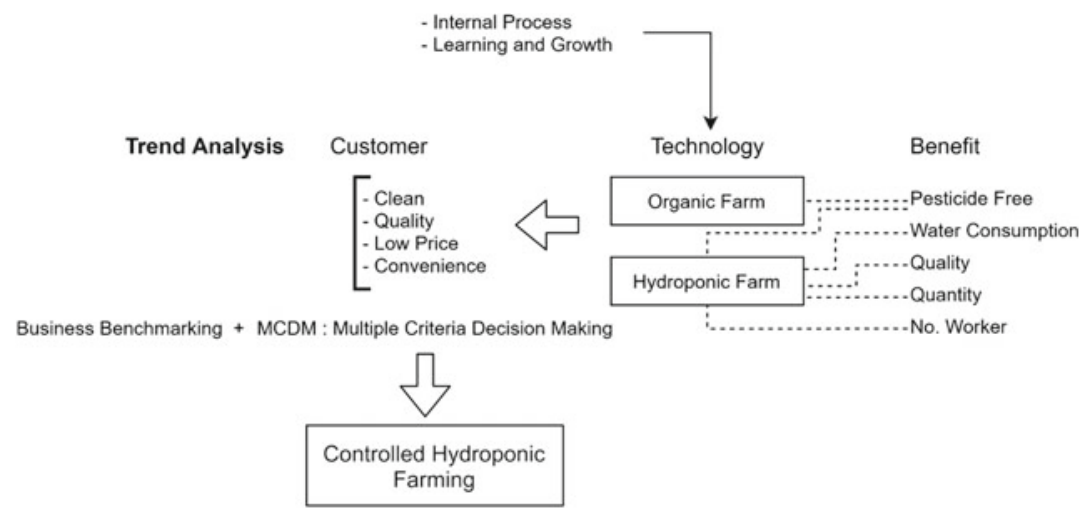

Fig. 12.7 Trend analysis of Agritech

\subsubsection{Plant Factory-The Foresight of Agritech Business}

The Business Foresight (see Fig. 12.8) suggests the investigation of the environmental analysis as there can be uncertainty and risk in the business foresight framework. In this case, the demand must meet the mass production capacity. The competitor and price also affect the competitiveness of the proposed business model. Moreover, there are risks, i.e., technological risk and operational risks. After scanning signal analysis, traditional Hydroponic planting techniques can be found limited in terms of productivity. A new scenario arises if the plant factory is more feasible.

The plant factory is categorized as one of the advanced agriculture systems which have been in the spotlight as a global prospect, owing to Industry 4.0 (Antonopoulos et al. 2019; Griffin et al. 2018; Katyal and Pandian 2020). This smart/precision farming allows fully autonomous planning, plowing, seed mapping, seeding, reseeding, and monitoring, using farming robots, sensors, IoT, and artificial intelligence (AI) (Zanwar and Kokate 2012). The technology is demanding due to the growing number of the world population but the shrinkage of arable land (Benke and Tomkins 2017). Not to mention the independence of 


\section{Environmental Analysis}

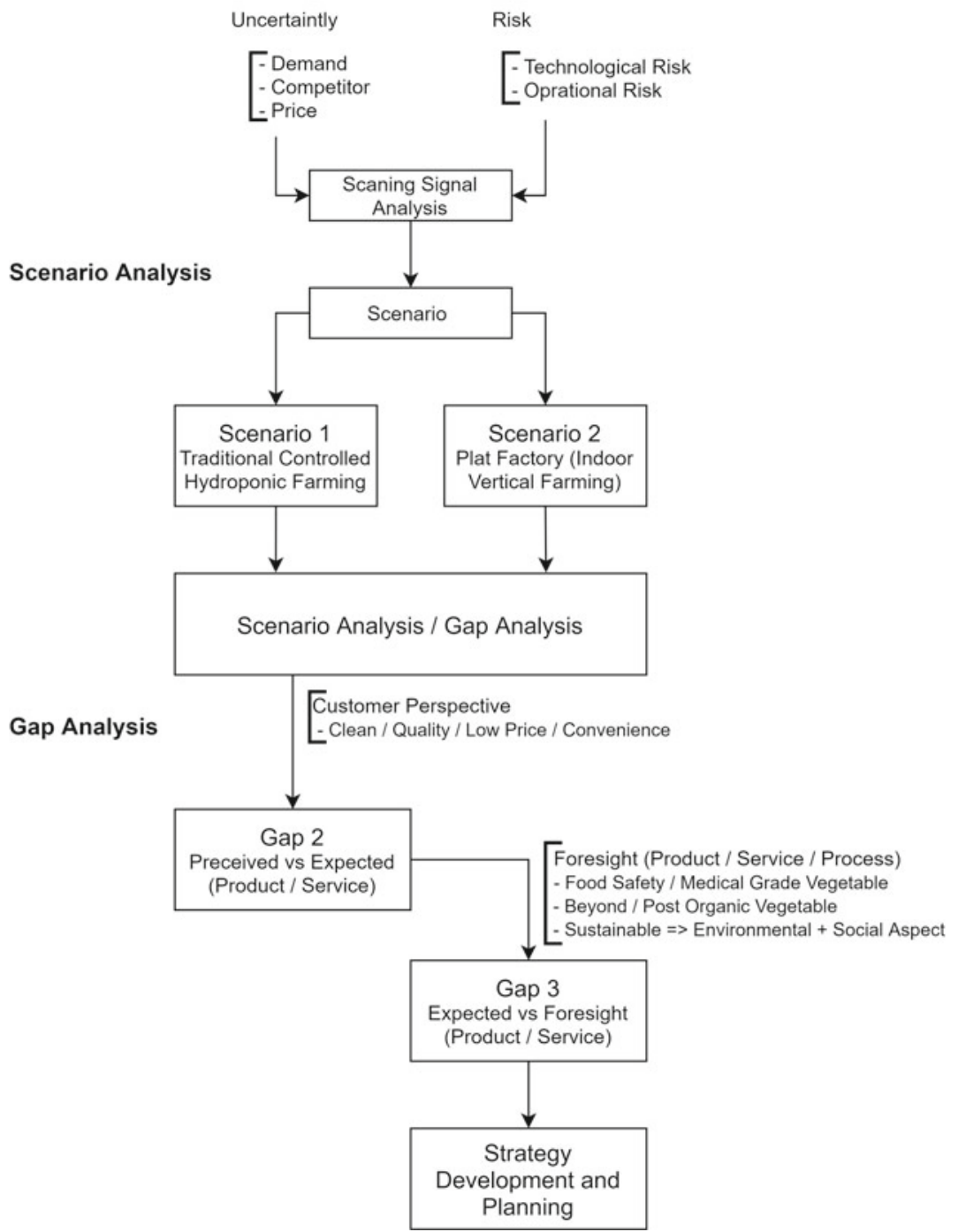

Fig. 12.8 Business foresight of Agritech 
the climate change that directly affects the productivity of the traditional outdoor cultivation.

In terminology, the plant factory is referred to the facility with an artificial cultivation environment, including light, wind, temperature, moisture, and carbon dioxide concentrations. The control production parameters give the independency of the crop to the outdoor climate, which favors the steady production of high-quality vegetables (Goto 2012, Kim 2010; Kozai et al. 2019). The plant factory can produce vegetables 4 times faster than by typical outdoor cultivation. The productivity and quality, in terms of size, taste, texture, can be maximized and controllable. The factory requires only a small site owing to the vertical farming technology (multiple cultivation shelves system) which allows mass production for the economy of scales. The plant factory leverages the concepts of hydroponics which can grow plants without soil (Resh 1995) and the organic agriculture (Badgley et al. 2007; Willer and Lernoud 2019) with Industry 4.0 technologies such as data-driven and IoT-based agriculture (Gondchawar and Kawitkar 2016; Leksakul et al. 2015; Ramingwong et al. 2011; Suma et al. 2017). Thus, the vegetable from the plant factory can be cost-effective, clean, pesticidefree, and sustainable (Benke and Tomkins 2017; Santiteerakul et al. 2020). The idea is aligned with Thailand 4.0 targeted industry and the newly promoted bio-economy, circular economy, and green economy (BCG) model.

On the global level, the plant factory has become very popular and has been well received by many countries. For example, in Japan, currently, there are more than 200 plant factories in the operation. Where the biggest plant factory in Japan is in Miyagi prefecture, this farm is 2300 sqm., equipped with 18 cultivation racks reaching 15 levels high, producing 10,000 heads of lettuce per day. In Taiwan, the plant factory related to Foxconn can produce a vegetable of 2.5 tons per day. The size of the factory is $5000 \mathrm{sqm}$. with 14 plantation shelves. The product is supplied to Foxconn's staff kitchen.

While considering gap analysis, the customer perspectives are set as the cleanness, quality, price, and convenience are the bottom lines. The plant factory can address those issues. In fact, the quality of the vegetable and the production cost are beyond the expectation. The vegetable from the 
plant factory can be classified as medical-grade or beyond/post organic. The water used in the factory is reversed osmosis. It is so clean, as to wash with tap water, it will be dirtier. The plant factory also addresses the sustainability issues as it uses much less water. It requires only $1 \%$ of water, which is normally used in an organic farm.

With the advancement of technology, skilled workers are the plant factory requirement. Advanced agricultural and engineering skills are demanded. These complex Industry 4.0 systems of CPS, IoT, AI, and Big Data are beyond traditional (Rauch 2020).

\subsubsection{Technology Blueprint Development-Plant Factory}

After the business model is firmly analyzed, the development plan proceeds. The second facility of the company is set up in Nakornnayok, $113 \mathrm{~km}$ north-east of Bangkok (see Fig. 12.9). The project was further financially supported by the National Innovation Agency (NIA). This plant factory is $160 \mathrm{sqm}$. (0.018 hectares) with 6-m high multiple shelves. It can accommodate 50,000 plants or 5 tons of vegetables per crop. It initially requires $21-30$ days per crop. The facility needs only 3 labor in operation. Moreover, the designed Standard Operating Procedure (SOP) allows individuals on the autism spectrum or elderly people to be able to work in this environment.

The facility has proven that the plant factory can be financial feasibility. Interestingly, the overall production cost can be low due to the capability to produce all-year-round. The plant factory can produce up
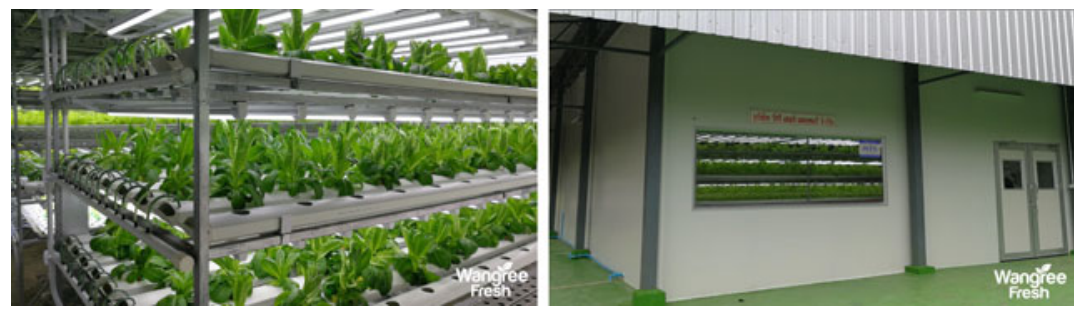

Fig. 12.9 Wangree plant factory in Nakornnayok, Thailand 
to 20 crops per year. The equipment is today efficient and assessable with a considerably low cost such as LED technology, sensors, controllers. In this facility, the technology assessment focusing on the plant factory was conducted. This so-called inside-out and outside-in approach industrial research was assisted by Chiang Mai University, Maejo University, Ministry of Digital Economy and Society and Ministry of Industry of Thailand, Delta Electronics (Thailand) Public Co., Ltd, ASEAN Coordinating Committee on Micro, Small, and Medium Enterprise (ACCMSME), Price water house Coopers Thailand (PwC Thailand), Japan External Trade Organization (JETRO), Ministry of Foreign Affairs and Ministry of SME, and Startups of the Korean government. After years of project pitching and experiments, different production parameters can be optimized using Big Data, including a close system, artificial lighting system, environment controlled (temperature and moisture), carbon dioxide concentration, wind speed and direction controlled, $\mathrm{PH}$ controlled system, and Percent oxygen concentration in water. The recipe is designed for each vegetable if desired.

The designed plant factory is fully automated, multi-shelves, and smart (see Fig. 12.10). The plant is a CPS where the physical layer comprises of Farm Gate Way (FGW) Unit that connects with application unit, i.e., automated multi-shelf system, cultivation robot, light control, water control, temperature and humidity sensor, carbon dioxide concentration sensor, wind speed, and direction sensor (see Fig. 12.11). Then the data is collected and analyzed using the Big Data engine. AI is used to plan cultivation, determine production parameters, and control crop management. Figure 12.12 illustrates the process of developing technology blueprint after technology assessment and gap analysis.

Current productivity is comparatively superior to the organic farm. It requires a much smaller area, less water, less labor. The overall unit cost is competitive. Quality is also more desirable. The vegetable size can be 2 times bigger than those of organic farms. Taste and texture can also be controlled.

This pilot 160 sq.m. plant factory with the production capacity is $160 \mathrm{~kg}$ per day. The infrastructure investment and technology acquiring are estimated as much as 6-m THB. However, the plant factory can 


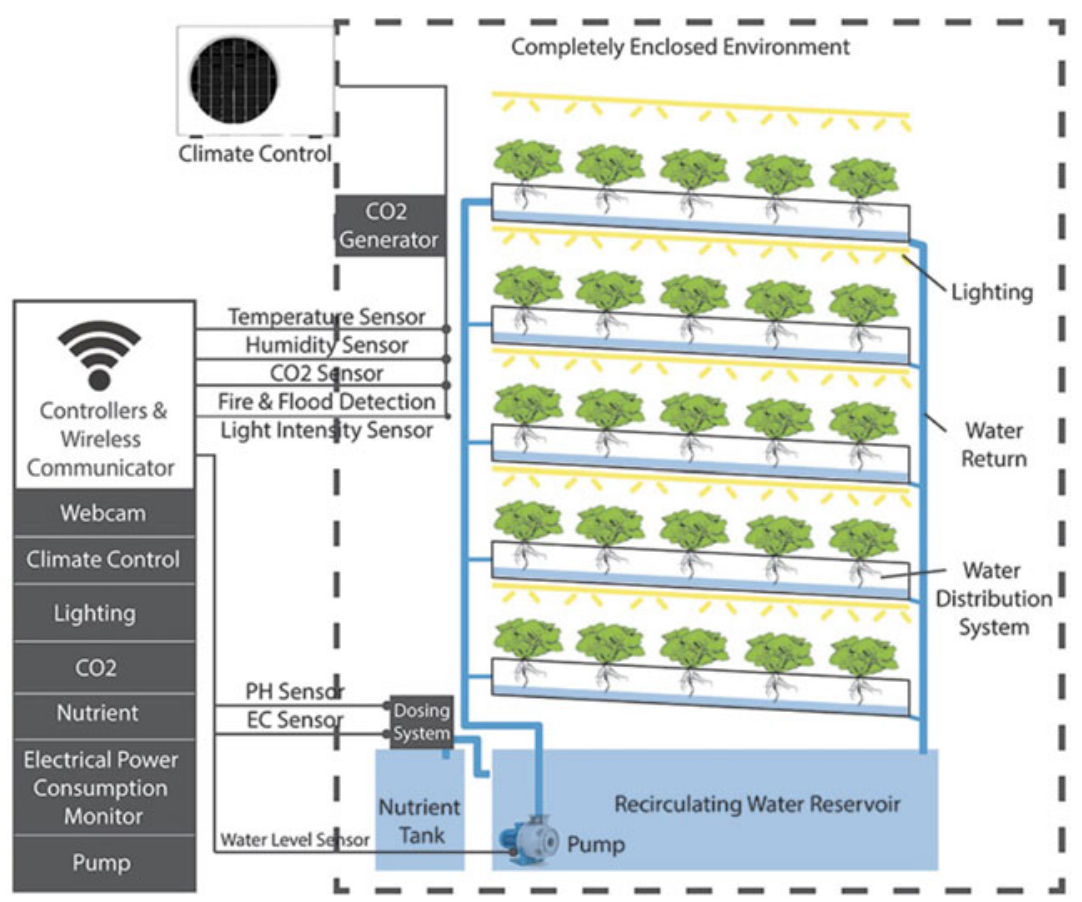

Fig. 12.10 Acquired technology in the plant factory of Agritech

generate a revenue of up to $3 \mathrm{~m}$ THB per month. The payback period can be as quick as 2 months.

\subsubsection{Requirement of New Skills-Addressing SME 4.0}

While the process can be fully automated, the number of operational workers can be reduced to minimal (Zsifkovits 2020). However, to design these sophisticating systems and advise the AI to the utmost efficiency (Woschank et al. 2020), multi-skill set workers are needed (Karacay 2018; Motyl et al. 2017). This includes professional technical production hard skills such as production management, logistics and supply chain engineering and management, robotics and automation 

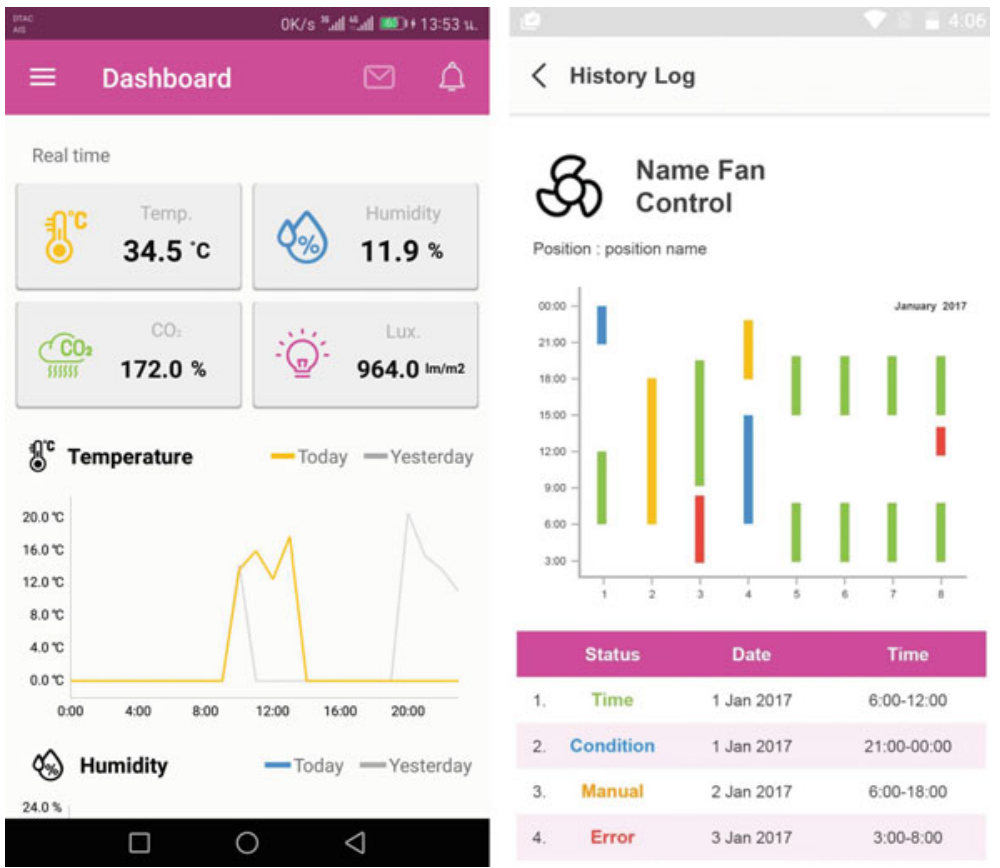

\begin{tabular}{|c|c|c|c|}
\hline & Status & Date & Time \\
\hline 1. & Time & 1 Jan 2017 & $6: 00-12: 00$ \\
\hline 2. & Condition & 1 Jan 2017 & $21: 00-00: 00$ \\
\hline 3. & Manual & 2 Jan 2017 & $6: 00-18: 00$ \\
\hline 4. & Error & 3 Jan 2017 & $3: 00-8.00$ \\
\hline
\end{tabular}

Fig. 12.11 Information systems developed for the plant factory Technology Assessment and
Technology Gap Analysis

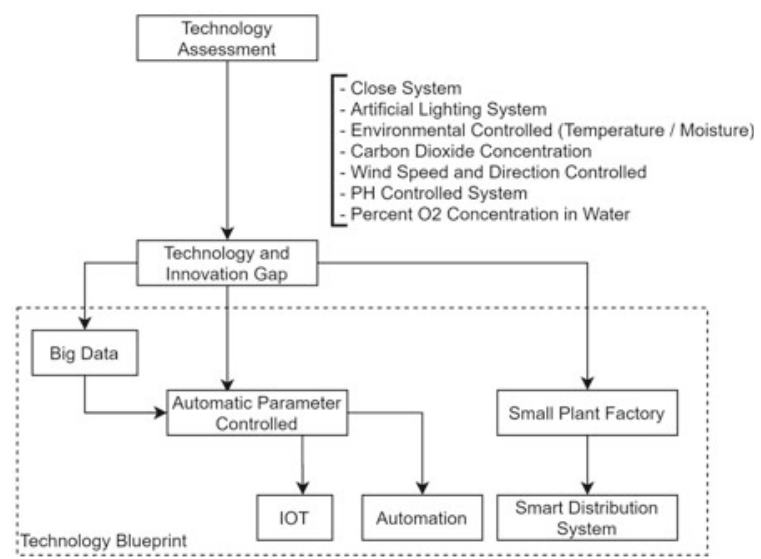

Fig. 12.12 Technology blueprint development of Agritech 
production, production technology, engineering material, work-study, and ergonomics. Other hard skills are also needed such as computer engineer including hardware, software, system, networking, information technology, data analytics as well as agriculture knowledge such as plant physiology. Moreover, soft skills and meta-skills are also needed such as problems solving and decision making, systematic thinking, data analytics, and reasoning skill, willing to learn and explore new knowledge, creativity and innovation, multidisciplinary transfer, and creative thinking and idea generation (Santiteerakul et al. 2019). Therefore, appropriate strategies for developing worker skill sets must be determined accordingly.

\subsubsection{Implementation Strategies for SME 4.0}

The company strategies are progressive. The market development strategy is adopted where there will be more satellite plant factories as the urban indoor farm. In the Bangkok area, the market is open and the demand is growing (Sukkarat and Athinuwat 2020). This comes with a distribution and logistics improvement to address the need of the customer. The packaging development is also an issue to maintain the freshness and the quality of the product. Further complete chain business model, e.g., Amazon Fresh model, YesHealth iFarm of Taiwan, must be examined.

On the other perspectives, the company has been researching with universities and tech-development agencies with various business opportunities. The plant factory is fit with the concept of superfood for cancer and blood pressure patients or low Potassium vegetable for kidney disease patient. Further R\&D can also lead to the production of edible vaccines (rabies vaccine, etc.), medical-grade Marijuana (Kumar et al. 2013; Sharma et al. 1999; Yao et al. 2015), Vitro meat (Bhat et al. 2015; Datar and Betti 2010). Figure 12.13 illustrates the processes of strategic development and planning. 


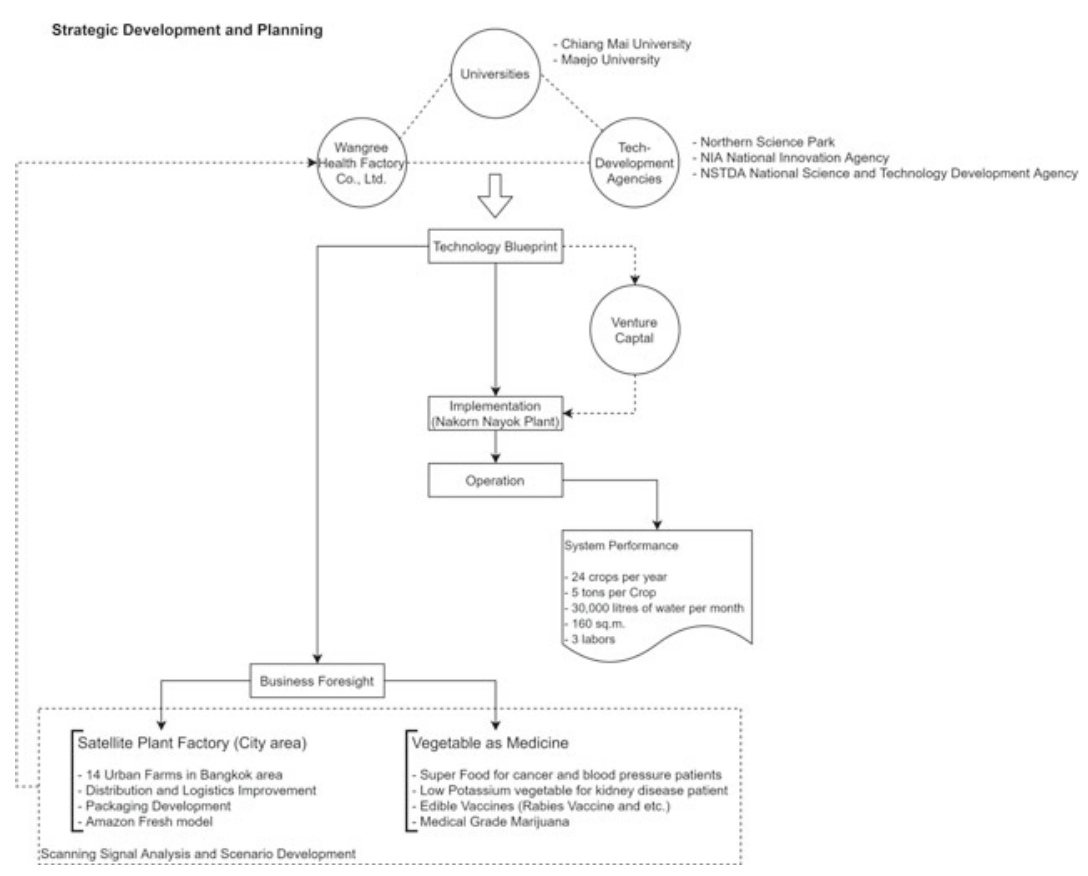

Fig. 12.13 Strategic development and planning of Agritech

\subsection{Discussion}

To review the targeted KPIs, the performance of the plant factory is benchmarked with organic and hydroponic farms. Table 12.1 summarizes the requirement with three different techniques of interest for producing 5 tons of vegetables per month.

Here, it can be seen that the plant factory is more desirable financially and more sustainable. However, skilled workers and advanced technology management can be critical as discussed.

Moreover, the business model is aligned with United Nations' Sustainable Development Goals (SDGs) (Stafford-Smith et al. 2017), i.e., zero hunger, good health and well-being, clean water and sanitation, affordable and clean energy, decent work and economic growth, industry, innovation and infrastructure, sustainable cities and communities, responsible consumption and production, climate action and life of land. 
Table 12.1 Performance of each advance agriculture techniques

\begin{tabular}{|c|c|c|c|}
\hline & Organic farm & Hydroponic farm & Plant factory \\
\hline $\begin{array}{l}\text { Specific } \\
\text { Requirement }\end{array}$ & $\begin{array}{l}\text { soil and } \\
\text { nutrient }\end{array}$ & $\begin{array}{l}\text { hard-infrastructure, } \\
\text { water, and } \\
\text { nutrient }\end{array}$ & $\begin{array}{l}\text { hard-infrastructure, } \\
\text { water and } \\
\text { nutrient, } \\
\text { multiple-shelf } \\
\text { system, and } \\
\text { automation system }\end{array}$ \\
\hline Land Use & 1.6 hectares & 0.96 hectares & 0.018 hectares \\
\hline $\begin{array}{l}\text { Water (Liter per } \\
\text { month) }\end{array}$ & 3 million & 1.8 million & 30,000 \\
\hline $\begin{array}{l}\text { Number of } \\
\text { workers }\end{array}$ & 20 & 20 & 3 \\
\hline $\begin{array}{l}\text { Product } \\
\text { Characteristic }\end{array}$ & $\begin{array}{l}\text { pesticide-free, } \\
\text { smaller size }\end{array}$ & $\begin{array}{l}\text { controllable size, } \\
\text { and R\&D } \\
\text { potential }\end{array}$ & $\begin{array}{l}\text { medical grade, } \\
\text { pesticide-free, } \\
\text { controllable size, } \\
\text { taste, and texture, } \\
\text { R\&D potential }\end{array}$ \\
\hline Crops per years & $6-8$ & $8-12$ & $12-20$ \\
\hline $\begin{array}{l}\text { Average Cost } \\
\text { per kg (THB) }\end{array}$ & $80-120$ & $50-70$ & 42.25 \\
\hline $\begin{array}{l}\text { Investment Cost } \\
\text { (million THB) }\end{array}$ & 12 & 10 & 6 \\
\hline $\begin{array}{l}\text { Payback period } \\
\text { (months) }\end{array}$ & 4 & 1.5 & 2 \\
\hline
\end{tabular}

The study demonstrates the use of the implementation strategies for SME 4.0 meta-model to the case study Thai Agritech SME. The company seeks a feasible business solution to address the demand for clean and quality fresh vegetables in Thailand. Following the first phases of analysis, which comprises business trend analysis, business foresight, and gap analysis, the case study company developed the business model of Plant Factory, which can utilize the benefit of Industry 4.0. New technology and investment are needed. Then to develop the plan, the company has been working in the triple-helix ecosystem. The company can then construct their technology blueprint to close the technology and innovation gap. Big Data as well as the Industry 4.0 concept leverages the production capability of the plant factory to be competitive to those other advanced agriculture systems. The new skill sets of labor are required to addressing the sophistication of this SME 4.0 including hard, 
soft, and meta-skills. Finally, the strategies are developed and planned as of further market expansion and evolution to Social start-up 4.0.

Acknowledgements This project has received funding from the European Union's Horizon 2020 research and innovation program under the Marie Skłodowska-Curie grant agreement No 734713. This research work was partially supported by Chiang Mai University-Thailand.

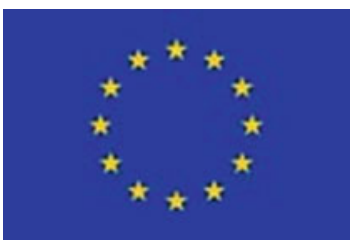

\section{References}

Antonopoulos, K., C. Panagiotou, C.P. Antonopoulos, and N.S. Voros. 2019. A-FARM Precision Farming CPS Platform. In 2019 10th International Conference on Information, Intelligence, Systems and Applications (IISA), pp. 1-3. https://doi.org/10.1109/IISA.2019.8900717.

Badgley, C., J. Moghtader, E. Quintero, E. Zakem, M.J. Chappell, K. AvilesVazquez, et al. 2007. Organic agriculture and the global food supply. Renewable agriculture and food systems, 86-108. https://doi.org/10.1017/S17 42170507001640.

Bär, K., Z.N.L. Herbert-Hansen, and W. Khalid. 2018. Considering Industry 4.0 aspects in the supply chain for an SME. Production Engineering 12 (6): 747-758. https://doi.org/10.1007/s11740-018-0851-y.

Benke, K., and B. Tomkins. 2017. Future food-production systems: Vertical farming and controlled-environment agriculture. Sustainability: Science, Practice and Policy 13 (1): 13-26. https://doi.org/10.1080/15487733.2017. 1394054.

Bhat, Z.F., S. Kumar, and H. Fayaz. 2015. In vitro meat production: Challenges and benefits over conventional meat production. Journal of Integrative Agriculture 14 (2): 241-248. https://doi.org/10.1016/S2095-3119(14)608 87-X. 
Brozzi, R., D. Forti, E. Rauch, and D. Matt. 2020. The advantages of industry 4.0 Applications for sustainability: Results from a sample of manufacturing companies. Sustainability 12: 3647. https://doi.org/10.3390/su12093647.

Chetthamrongchai, P., and K. Jermsittiparsert. 2020. Ensuring environmental performance of pharmaceutical companies of Thailand: Role of robotics and $\mathrm{AI}$ awareness and technical content knowledge in industry 4.0 era. Systematic Reviews in Pharmacy 11 (1): 129-138. https://doi.org/10.5530/srp.2020. 1.18 .

Chinachoti, P. 2018. The readiness of human resource management for industrial business sector towards industrial 4.0 in Thailand. Asian Administration \& Management Review 1 (2). https://ssrn.com/abstract=3269079.

Chonsawat, N., and A. Sopadang. 2019. The development of the maturity model to evaluate the smart SMEs 4.0 readiness. In Proceedings of the International Conference on Industrial Engineering and Operations Management. Bangkok, Thailand.

Dallasega, P., M. Woschank, S. Ramingwong, K.Y. Tippayawong, and N. Chonsawat. 2019. Field study to identify requirements for smart logistics of European, US and Asian SMEs. In Proceedings of the International Conference on Industrial Engineering and Operations Management. Bangkok, Thailand.

Datar, I., and M. Betti. 2010. Possibilities for an in vitro meat production system. Innovative Food Science \& Emerging Technologies 11 (1): 13-22. https://doi.org/10.1016/J.IFSET.2009.10.007.

Gabriel, M., and E. Pessl. 2016. Industry 4.0 and sustainability impacts: Critical discussion of sustainability aspects with a special focus on future of work and ecological consequences. Annals of the Faculty of Engineering Hunedoara-International Journal of Engineering 14 (2): 131-136.

Galvao, A., C. Mascarenhas, C. Marques, J. Ferreira, and V. Ratten. 2019. Triple helix and its evolution: A systematic literature review. Journal of Science and Technology Policy Management 10 (3): 812-833. https://doi.org/ 10.1108/JSTPM-10-2018-0103.

Ganzarain, J., and N. Errasti. 2016. Three stage maturity model in SME's toward industry 4.0. Journal of Industrial Engineering and Management 9 (5): 1119-1128. http://dx.doi.org/10.3926/jiem.2073.

Gilchrist, A. 2016. Introducing industry 4.0. In Industry 4.0. Berkeley, CA: Apress. https://doi.org/10.1007/978-1-4842-2047-4_13.

Gondchawar, N., and R.S. Kawitkar. 2016. IoT based smart agriculture. International Journal of Advanced Research in Computer and Communication Engineering 5 (6): 838-842. https://doi.org/10.1109/ACCESS.2019. 2932609. 
Goto, E. 2012. Plant production in a closed plant factory with artificial lighting. In VII International Symposium on Light in Horticultural Systems, 956. https://doi.org/10.17660/ActaHortic.2012.956.2.

Griffin, T.W., J.M. Shockley, and T.B. Mark. 2018. Economics of precision farming. Precision Agriculture Basics, 221-230. https://doi.org/10.2134/pre cisionagbasics.2016.0098.

Hanafizadeh, P., and A.Z. Ravasan. 2011. A McKinsey $7 \mathrm{~S}$ model-based framework for ERP readiness assessment. International Journal of Enterprise Information Systems 7 (4): 23-63. https://doi.org/10.4018/jeis.2011100103. Hotrawaisaya, C., V. Pakvichai, and T. Sriyakul. 2019. Lean production determinants and performance consequences of implementation of industry 4.0 in Thailand: Evidence from manufacturing sector. International Journal of Supply Chain Management 8 (5): 559. https://doi.org/10.13140/RG.2.2. 16491.69929.

Jazdi, N. 2014. Cyber physical systems in the context of Industry 4.0. In IEEE International Conference on Automation, Quality and Testing, Robotics. https:// doi.org/10.1109/AQTR.2014.6857843.

Jones, C., and P. Pimdee. 2017. Innovative ideas: Thailand 4.0 and the fourth industrial revolution. Asian International Journal of Social Sciences 17 (1): 4-35. https://doi.org/10.29139/aijss.20170101.

Kaplan, R.S., and D.P. Norton. 1998. Putting the balanced scorecard to work. The Economic Impact of Knowledge 27 (4): 315-324.

Karacay, G. 2018. Talent development for industry 4.0. In Industry 4.0: Managing the digital transformation. Cham: Springer Series in Advanced Manufacturing, Springer. https://doi.org/10.1007/978-3-319-57870-5_7.

Katyal, N., and B.J. Pandian. 2020. A comparative study of conventional and smart farming. In Emerging technologies for agriculture and environment. Singapore: Springer. https://doi.org/10.1007/978-981-13-7968-0_1.

Kim, J.W. 2010. Trend and direction for plant factory system. Journal of Plant Biotechnology 37 (4): 442-455. https://doi.org/10.5010/JPB.2010.37. 4.442 .

Kohpaiboon, A. 2020. Industry 4.0 policies in Thailand. Economic Working Paper 2020-02.

Korkueasuebsai, O., and C. Pornsing. 2018. A study of factors and effects of Industry 4.0 policy on Thai electronics industry (Doctoral dissertation, Silpakorn University). http://ithesis-ir.su.ac.th/dspace/handle/123456 789/1783.

Kozai, T., G. Niu, and M. Takagaki. 2019. Plant factory: An indoor vertical farming system for efficient quality food production. Academic Press. 
Kumar, B.V., T.K. Raja, M.R. Wani, S.A. Sheikh, M.A. Lone, G. Nabi, et al. 2013. Transgenic plants as green factories for vaccine production. African Journal of Biotechnology 12 (43): 6147-6158. https://doi.org/10.5897/AJB 2012.2925.

Kumpirarusk, P. and K. Rohitratana. 2018. Industry 4.0: Future industries of Thailand. WMS Journal of Management 7 (3): 52-64. https://so06.tci-tha ijo.org/index.php/wms/article/view/147021.

Laosiritaworn, W., and W. Chattinnawat. 2019. Industry 4.0 gap analysis for Thai industries with association rules mining. In Proceedings of the International Conference on Industrial Engineering and Operations Management. Bangkok, Thailand.

Lasi, H., P. Fettke, H.G. Kemper, T. Feld, and M. Hoffmann. 2014. Industry 4.0. Business \& Information Systems Engineering 6 (4): 239-242. https://doi. org/10.1007/s12599-014-0334-4.

Lee, J., B. Bagheri, and H.A. Kao. 2015. A cyber-physical systems architecture for industry 4.0-based manufacturing systems. Manufacturing Letters 3: 1823. https://doi.org/10.1016/j.mfglet.2014.12.001.

Leksakul, K., P. Holimchayachotikul, and A. Sopadang. 2015. Forecast of off-season longan supply using fuzzy support vector regression and fuzzy artificial neural network. Computers and Electronics in Agriculture 118: 259-269. https://doi.org/10.1016/j.compag.2015.09.002.

Leydesdorff, L. 2010. The knowledge-based economy and the triple helix model. Annual Review of Information Science and Technology 44 (1): 365417. https://doi.org/10.1002/aris.2010.1440440116.

Lu, Y. 2017. Industry 4.0: A survey on technologies, applications and open research issues. Journal of Industrial Information Integration 6: 1-10. https:// doi.org/10.1016/j.jii.2017.04.005.

Matt, D.T., and E. Rauch. 2020. SME 4.0: The role of small-and mediumsized enterprises in the digital transformation. In Industry 4.0 for SMEs: Challenges, opportunities and requirements. Cham: Palgrave Macmillan. https://doi.org/10.1007/978-3-030-25425-4_1.

Mihiotis, A. 2014. Management of supply chain: X-to-order concepts vs maketo-stock model. International Journal of Business Administration 5 (3): 30. https://doi.org/10.5430/ijba.v5n3p30.

Modrak, V., Z. Soltysova, and R. Poklemba. 2019. Mapping requirements and roadmap definition for introducing I 4.0 in SME environment. In Advances in manufacturing engineering and materials. Cham: Springer. https://doi.org/ 10.1007/978-3-319-99353-9_20. 
Motyl, B., G. Baronio, S. Uberti, D. Speranza, and S. Filippi. 2017. How will change the future engineers' skills in the Industry 4.0 framework? A questionnaire survey. Procedia Manufacturing 11: 1501-1509. https://doi. org/10.1016/j.promfg.2017.07.282.

Munkongsujarit, S. 2016. Business incubation model for startup company and SME in developing economy: a case of Thailand. In 2016 Portland International Conference on Management of Engineering and Technology. IEEE. https://doi.org/10.1109/PICMET.2016.7806786.

Nakwa, K., and G. Zawdie. 2016. The 'third mission' and 'triple helix mission' of universities as evolutionary processes in the development of the network of knowledge production: Reflections on SME experiences in Thailand. Science and Public Policy 43 (5): 622-629. https://doi.org/10.1093/scipol/ scw030.

Pérez, J.D.C., R.E.C. Buitrón, and J.I.G. Melo. 2018. Methodology for the retrofitting of manufacturing resources for migration of SME towards industry 4.0. In International Conference on Applied Informatics. Springer, Cham.

Phungphol, W., S. Tumad, K. Sangnin, and S. Pooripakdee. 2018. Creating passion for preparedness of automotive industry entrepreneurs for industry 4.0 era in the Southern part of Thailand. International Journal of Business and Economic Affairs 3 (1): 1-12. https://doi.org/10.24088/IJBEA-201831001.

Prause, G. 2015. Sustainable business models and structures for Industry 4.0. Journal of Security \& Sustainability Issues 5 (2). https://doi.org/10.9770/jssi. 2015.5.2(3).

Ramingwong, S., and W. Manopiniwes. 2019. Supportment for organization and management competences of ASEAN community and European Union toward Industry 4.0. International Journal of Advanced and Applied Sciences 6 (3): 96-101. https://doi.org/10.21833/ijaas.2019.03.014.

Ramingwong, S., W. Manopiniwes, and V. Jangkrajarng. 2019. Human factors of Thailand toward industry 4.0. Management Research and Practice 11 (1): $15-25$.

Ramingwong, S., K.Y. Tippayawong, and A. Sopadang. 2011. On the development of I-community to improve production of off-season longan. Australian Journal of Basic and Applied Sciences 5 (10): 649-654.

Rauch, E. 2020. Industry 4.0+: The next level of intelligent and self-optimizing factories. Book Advances in Design, Simulation and Manufacturing 3: 176186. https://doi.org/10.1007/978-3-030-50794-7_18. 
Rauch, E., M. Unterhofer, R. Rojas, L. Gualtieri, M. Woschank, and D. Matt. 2020. a maturity level-based assessment tool to enhance the implementation of industry 4.0 in small and medium-sized enterprises. Sustainability 12: 1-18. https://doi.org/10.3390/su12093559.

Resh, H. M. 1995. Hydroponic food production. A definitive guidebook of soilless food-growing methods (No. Ed. 5). Woodbridge Press Publishing Company.

Rohrbeck, R. 2010. Corporate foresight: Towards a maturity model for the future orientation of a firm. In Springer series: Contributions to management science. Heidelberg and New York.

Rohrbeck, R., C. Battistella, and E. Huizingh. 2015. Corporate foresight: An emerging field with a rich tradition. Technological Forecasting and Social Change 101: 1-9. https://doi.org/10.1016/j.techfore.2015.11.002.

Rüßmann, M., M. Lorenz, P. Gerbert, M. Waldner, J. Justus, P. Engel, and M. Harnisch. 2015. Industry 4.0: The future of productivity and growth in manufacturing industries. Boston Consulting Group 9 (1): 54-89.

Safar, L., J. Sopko, S. Bednar, and R. Poklemba. 2018. Concept of SME business model for industry 4.0 environment. TEM Journal 7 (3): 626. https:// doi.org/10.18421/TEM73-20.

Santiteerakul, S., A. Sopadang, and A. Sekhari. 2019. Skill Development for Industrial Engineer in Industry 4.0. In Proceedings of IEEE-15th ChinaEurope International Symposium on Software Engineering Education. LisbonCaparica, Portugal.

Santiteerakul, S., A. Sopadang, K.Y. Tippayawong, and K. Tamvimol. 2020. The role of smart technology in sustainable agriculture: A case study of Wangree plant factory. Sustainability 12: 4640. https://doi.org/10.3390/su1 2114640.

Sharma, A.K., A. Mohanty, Y. Singh, and A.K. Tyagi. 1999. Transgenic plants for the production of edible vaccines and antibodies for immunotherapy. Current Science 77 (4): 524-529.

Singh, A. 2013. A study of role of McKinsey's 7S framework in achieving organizational excellence. Organization Development Journal 31 (3): 39.

SME4.0. 2020. SME4.0 Project Objectives. http://www.sme40.eu/. Accessed on 10 June 2020.

Sopadang, A., N. Chonsawat, and S. Ramingwong. 2020. Smart SME 4.0 implementation toolkit. In Industry 4.0 for SMEs: Challenges, opportunities and requirements. Cham: Palgrave Macmillan. https://doi.org/10.1007/9783-030-25425-4_10. 
Stafford-Smith, M., D. Griggs, O. Gaffney, F. Ullah, B. Reyers, N. Kanie, N., et al. 2017. Integration: The key to implementing the Sustainable Development Goals. Sustainability Science 12 (6): 911-919. https://doi.org/10. 1007/s11625-016-0383-3.

Stubbs, W., and C. Cocklin. 2008. Conceptualizing a "sustainability business model". Organization \& Environment 21 (2): 103-127. https://doi.org/10. 1177/1086026608318042.

Sukkarat, K., and D. Athinuwat. 2020. Study of consumption behavior and attitude of organic product consumer (in Thai). Thai Journal of Science and Technology 9 (1). https://doi.org/10.14456/tjst.2020.6.

Suma, N., S.R. Samson, S. Saranya, G. Shanmugapriya, and R. Subhashri. 2017. IOT based smart agriculture monitoring system. International Journal on Recent and Innovation Trends in Computing and Communication 5 (2): 177-181. https://doi.org/10.35940/ijitee.I7142.079920.

Tippayawong, K.Y., N. Niyomyat, A. Sopadang, and S. Ramingwong. 2016. Factors affecting green supply chain operational performance of the Thai auto parts industry. Sustainability 8 (11): 1161. https://doi.org/10.3390/ su8111161.

Tippayawong, K.Y., S. Santiteerakul, S. Ramingwong, and N. Tippayawong. 2019. Cost analysis of community scale smokeless charcoal briquette production from agricultural and forest residues. Energy Procedia 160: 310-316. https://doi.org/10.1016/j.egypro.2019.02.162.

Willer, H., and J. Lernoud. 2019. The world of organic agriculture. Statistics and emerging trends 2019. Research Institute of Organic Agriculture FiBL and IFOAM Organics International.

Woschank, M., E. Rauch, and H. Zsifkovits. 2020. A review of further directions for artificial intelligence, machine learning, and deep learning in smart logistics. Sustainability 19: 1-23. https://doi.org/10.3390/su12093760.

Yao, J., Y. Weng, A. Dickey, and K.Y. Wang. 2015. Plants as factories for human pharmaceuticals: Applications and challenges. International Journal of Molecular Sciences 16 (12): 28549-28565. https://doi.org/10.3390/ijm s161226122.

Zanwar, S.R., and R.D. Kokate. 2012. Advanced agriculture system. International Journal of Robotics and Automation 1 (2): 107-112. https://doi.org/ 10.11591/ijra.v1i2.382.

Zsifkovits, H., M. Woschank, S. Ramingwong, and W. Wisittipanich. 2020. State-of-the-art analysis of the usage and potential of automation in logistics. 
In Industry 4.0 for SMEs: Challenges, opportunities and requirements. Cham: Palgrave Macmillan. https://doi.org/10.1007/978-3-030-25425-4_7.

Open Access This chapter is licensed under the terms of the Creative Commons Attribution 4.0 International License (http://creativecommons.org/ licenses/by/4.0/), which permits use, sharing, adaptation, distribution and reproduction in any medium or format, as long as you give appropriate credit to the original author(s) and the source, provide a link to the Creative Commons license and indicate if changes were made.

The images or other third party material in this chapter are included in the chapter's Creative Commons license, unless indicated otherwise in a credit line to the material. If material is not included in the chapter's Creative Commons license and your intended use is not permitted by statutory regulation or exceeds the permitted use, you will need to obtain permission directly from the copyright holder. 